\title{
DEVELOPMENT AND TESTING OF GLOW-IN-THE-DARK CONCRETE BASED RAISED PAVEMENT MARKER FOR IMPROVED TRAFFIC SAFETY
}

\author{
Muhammad SALEEM ${ }^{\circledR} 1^{*}$, Akira HOSODA ${ }^{2}$ \\ ${ }^{1}$ Department of Mechanical and Energy Engineering, College of Engineering, Imam Abdulrahman Bin Faisal \\ University, P.O. Box 1982, Dammam 31441, Eastern Province, Kingdom of Saudi Arabia \\ ${ }^{2}$ Institute of Urban Innovation, Yokohama National University, 79-1 Tokiwadai, Hodogaya Ward, \\ Yokohama, Kanagawa 240-8501, Japan
}

Received 16 December 2020; accepted 21 April 2021

\begin{abstract}
Road infrastructure has witnessed incremental changes in the past as compared to the immense development witnessed by the vehicle's safety technology. Bott's dots and other reflector devices are extensively used on the road infrastructure for lane separation and for improving edge detection. These devices come in a large variety of shapes and sizes, however, all of them fall under the category of retroreflectivity since they depend on vehicle lights to provide reflection. Glow-in-the-dark (GiD) material has the benefit that it can store energy during the presence of light and can emit the stored energy in the form of visible light in the absence of an external light source. In this regard, the presented research work details the development and testing of $\mathrm{GiD}$ concrete based markers that can be used for lane separation and edge detection. The benefit of the presented innovation is that GiD concrete based markers can be used for visible light instead of retroreflectivity in addition to acting as a driver alertness tool. The durability performance of the presented innovative GiD based raised pavement markers has been presented along with cost comparison to traditional Bott's dot. In addition, the presented prototype can be adopted for various architectural and esthetical applications in buildings, parks, walkways and bicycle lanes etc.
\end{abstract}

Keywords: glow-in-the-dark concrete, traffic safety, construction materials, infrastructure design, performance testing, road furniture.

\section{Introduction}

Traffic safety is a major concern around the world. Modern vehicles are a marvel of engineering with sensors, camera and cruise control included to assist the driver in their commute (Euro NCAP, 2020). Jarašūnienè and Jakubauskas (2007) highlighted the use of intelligent vehicle safety systems by dividing them into active and passive safety features. The researchers concluded that the improvement of road infrastructure was necessary to improve safety. Teo \& Tan (2020) investigated the use of smart helmet with object detection for allowing the road users to identify signs and road furniture. However, the road infrastructure has seen little development in recent decades. Providing streetlight for the nighttime traffic safety is a major challenge. Globally around $2.3 \%$ of electricity generated is utilized for street lighting purposes (Kostic \& Djokic, 2009). The lack of night lighting on roads has been a source of negative impact on road users (STG Aerospace, 2020). The specifications for providing nighttime lighting on the roads date back almost a century ago (British Standards Institution, 1927). Several options have been explored in the past to resolve the nighttime visibility issue which range from providing glass/acrylic beads, paint marking, LEDs, raised pavement reflectors etc. (Utah Department of Transportation, 2012; State of California Department of Transportation, 2018). No single solution has been universally acceptable; however, each has its advantages and disadvantages.

Recently, an idea of incorporating solar panels into the road surface was developed in the USA as shown in Figure 1 , the proposed solution was also tested on highways in China (Mai, 2018). The aim of the researchers was to generate electricity from the road surface and use the generated energy to power streetlights (Solar Roadways Incorporated, 2020). However, the idea is at early stages of development and faces challenges such as extreme environmental conditions and heavy traffic loading (Mai, 2018).

*Corresponding author. E-mails: mssharif@iau.edu.sa, c.engineeer@hotmail.com 


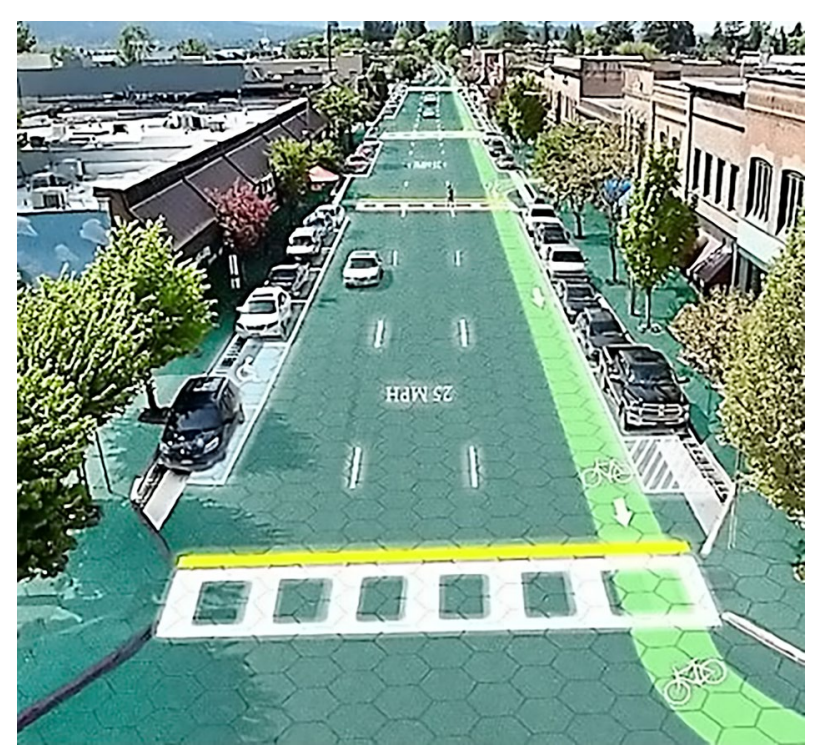

Figure 1. Hexagonal Solar Panels with toughened glass installed on road surface (Solar Roadways Incorporated, 2020)

Saleem and co-authors (Saleem, 2016, 2020; Saleem et al., 2017; Saleem \& Blaisi, 2019), developed a smart road lane separator that can transmit information to the road users and were able to sustain the harsh road loading and environment (Appendix). The aim of the researchers was to provide information to the road users through light transmitted from under the road surface. However, the idea is yet to be tested under real-world conditions.

Photoluminescent material also known as glow-in-thedark material offer a solution to lack of nighttime visibility problem by providing visible light for lane separation and edge detection of roadways. Luminescence is a physical property of living being and materials which gives them the ability to produce visible light in the absence of an external light. Phosphorescence is a form of photoluminescence which releases the absorbed radiation slowly in the form of visible light. Energy is absorbed in terms of solar radiation, even streetlights and light coming from the vehicles can contribute to energy absorption. In materials this phenomenon is achieved by using light irradiation to excite the electrons. It is the fundamental property of materials that when electrons change direction, they release energy (Blamire, 2003; Britannica, 2020). This released energy can be harnessed for providing nighttime visibility on road pavements.

Commercial companies in the Netherlands have been working on developing photoluminescent paints that has the ability to glow during the nighttime for up to $10 \mathrm{hrs,}$ thus providing free road lighting (Rojas-Hernandez et al., 2018; Praticò et al., 2016). Depending upon the technological advances and improvements in performance and durability, this type of lighting source could be used to enhance the road safety along with lowering the urban heat island effects (Giuliani \& Autelitano, 2014; Okada, 2015). To consider photoluminescent material for application on road infrastructure, it is necessary to understand their effect in terms of safety, environmental influence and sustainability (Cafiso \& D'Agostino, 2016). Santamouris (2013) and Praticò et al. (2018), investigated the advantage and dis-advantage of photoluminescent road coatings for open-graded and dense-graded asphalts in order to judge their illuminance and texture decay resulting in friction decrease. The researchers concluded that the paint applied to the surface undergoes drain-down effect thereby flowing into the voids of the asphalt thus limiting the amount of paint application.

Various types of materials are used for marking road pavements such as paint, tape and sprays (Bahar et al., 2006; Nance \& Sparks, 2020a; Praticò et al., 2016). Researchers have shown that the application of GiD material in the form of paint coating can have poor durability with paint application eroding in 0.7-2.5 years (Sathyanarayanan, 2007; Wiese et al., 2015). The technical requirements of marking are skid resistance, reflectivity during the daytime and retroreflectivity i.e., reflection during the nighttime under the headlamps of the vehicles. Photoluminescent paints generally contain (a) butyl ethanoate, a colorless flammable ester at room temperature, (b) xylene or ethylbenzene which are an aromatic hydrocarbon. Nanophosphor, strontium aluminate is an inert, odorless, nonflammable crystalline powder. It is heavier than water and when activated using europium $\left(\mathrm{SrAl}_{2} \mathrm{O}_{4}\right.$ : Eu) dopant, it acts as a slow discharge photoluminescent phosphor. It is commonly used in exit signs, stairways, pathways along with safety markings (Zitoun et al., 2009; Nance \& Sparks, 2020b).

Currently, the road furniture such as raised lane reflector and separators are designed to provide retroreflectance to the road users by reflecting light coming from the vehicle's head lights to give feedback to the road users regarding lane change and road edge. Glass beads are commonly employed in various specification based on their retroreflective properties and low cost. Retroreflective properties of glass beads have been a topic of interest in recent times. Smadi et al. (2014) summarized the parametric impact on the light reflectivity of glass beads. The influential factors that affect the performance of paints that contain glass beads were categorized as (a) type of binder; (b) surface conditions; (c) quality and quantity of glass beads material in marking paint; (d) embedment and roll. Researchers concluded that there was large variation in performance of the paint materials owing to uncontrollable factors such as type of binder, surface conditions and large temperature variations. Another drawback of glass bead reflector is their reduced visibility via retroreflection during rain and standing water on the road surface (Smadi et al., 2014; Hautière et al., 2009).

In this regard, glow-in-the-dark (GiD) materials offer a unique opportunity to researchers and engineers seeking innovation in materials to improve the performance capabilities of existing design of raised pavement markers. Figure 2 presents the picture of a glow-in-the-dark highway unveiled in the Netherlands. GiD material has been adopted for edge detection on dark highways by em- 


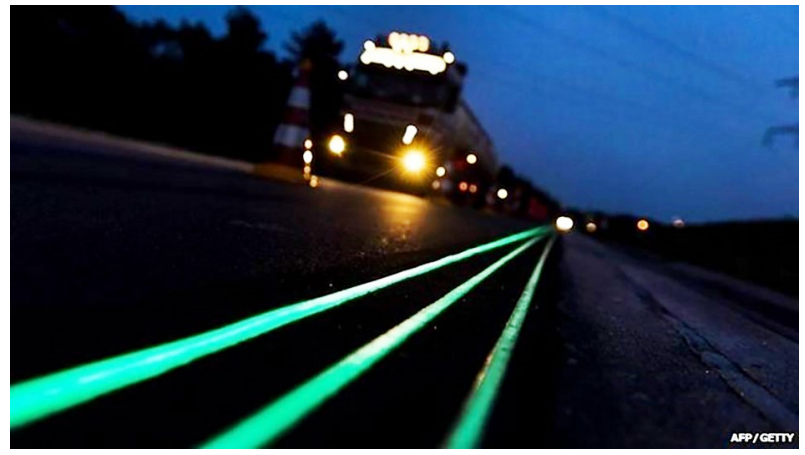

Figure 2. Glow-in-the-dark highway in Netherlands (McGrath, 2014; BBC News, 2014b)

bedding electrical wires under the layer of $\mathrm{GiD}$ paint. The drawback of this technique is that the GiD material requires an electrical current to be excited which leads to the glowing effect. On-site testing revealed that the material has the ability to glow for 12 hours, however, its durability and performance under harsh environmental conditions is lower than the expected level (McGrath, 2014; BBC News, 2014a, 2014b). Nance and Sparks (2020b) presented a detailed review into the potential application phosphorescent materials for lighting up the tomorrow's highways and presented detail of the various challenges involved with their application. The researchers highlighted the need of further research and development on this topic.

In light of the above presented discussion the aim of the presented research work was to develop a GiD material based raised pavement marker (RPM) that can be used for lane separation and edge detection. The manuscript details the proof-of-concept regrading design and performance testing of GiD based RPM. The proposed solution circumvents the durability challenges posed by the photoluminescent paint. The developed prototype has the ability to glow for $8 \mathrm{hrs}$ after light excitation thus eradicating the need for electroluminesce. Performance testing including thermo-mechanical testing and skid resistance testing was performed on the developed prototype in order to judge its suitability under real-world condition. Furthermore, cost comparison of GiD based pavement markers is presented to show the increase in cost as compared to the traditional markers such as Bott's dots, buttons, turtles etc. available in the market.

\section{Objectives}

The research work details the use of nanophosphor Strontium Aluminate as GiD nano-powder along with resinbased epoxy used to develop GiD based pavement marker. Figure 3 presents the day and night view of the nano powder. The main objectives of the presented experimental research work are as provided below:

1) To develop a proof-of-concept prototype of GiD based RPM with capability of providing visible light as compared to traditional retroreflectance from RPMs.

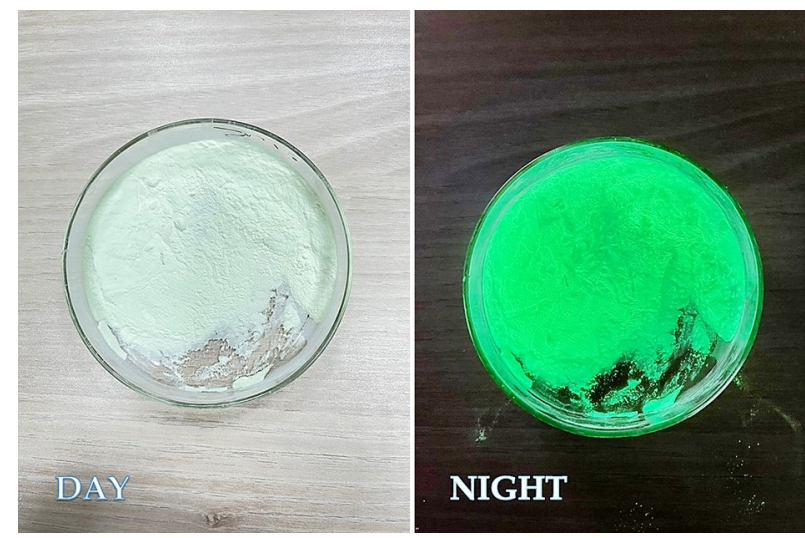

Figure 3. Day and nighttime view Glow-in-the-dark (GiD) material

2) To experimentally investigate the optimum percentage of $\mathrm{GiD}$ powder required to achieve the desired glow duration and intensity.

3) To perform durability testing on the developed prototype.

\section{Design}

Commercially available Bott's dots, turtles, buttons, and reflectors come in a large variety of shapes and sizes. This large variation in shape and size is attributed to speed and volume of traffic on a given highway. Through field investigation it was noticed that the most common cause of failure of the commercially available Bott's dots is breakage, dismantling and slippery top surface leading to poor grip of tires (Texas Transportation Institute, 2009; American Association of State Highway and Transportation Officials [AASHTO] 2007; National Aeronautics and Space Administration [NASA], 2020). Their main function as road furniture is to provide retroreflectance and to serve as a driver alerting tool when changing lane or nearing the edge of the road. Hence, the fundamental advancement of the presented GiD RPM over the traditional RPMs is its ability to provide safety inform of visible light during the nighttime in-addition to acting as a driver alertness tool.

While choosing the shape and size of the presented prototype, detailed discussion was held with field engineers working in the road maintenance industry along with detailed literature survey. The discussions consisted of survey questions and feedback from stakeholders which included government entities, private consulting and design organizations along with academic researchers. Learning from the feedback of the participants the criterion for selecting the shape and size of GiD RPM was based upon (a) glow-in-the-dark visibility; (b) driver alertness; (c) ease of manufacturing; (d) transport and installation along with roughness of the top-surface.

In light of the above presented background, a circular shape with $75 \mathrm{~mm}$ diameter and $15 \mathrm{~mm}$ height having a defined vertical edge was chosen as the final design of the proposed prototype. The objective of this design is to provide driver feedback in term of tire vibration and 
safety through glow-in-the-dark. The prototype presented in the manuscript is selected for application on roads with vehicle speeds of maximum $50 \mathrm{~km} / \mathrm{hr}$. Although several sizes and shapes are possible for the proposed GiD RPM, however, the aim of the presented research work is to act as proof-of-concept for GiD RPM. Hence, only one road type was selected owing to budgetary constraints. The design for other higher speed roads is an area for further research and development.

\section{Materials}

GiD based raised pavement marker disk specimens were molded by preheating the die to $150{ }^{\circ} \mathrm{C}$ for 15 mins and placing a layer of GiD nano powder followed by a $5 \mathrm{~mm}$ layer of methyl ester polystyrene here onwards referred to as epoxy resin. A steel meshing of $1 \mathrm{~mm}$ diameter with 4 $\mathrm{mm}$ center to center spacing was placed along with second layer $\mathrm{GiD}$ nano powder followed by $10 \mathrm{~mm}$ of epoxy resin. The structure of the wire mesh was incorporated into the specimen in order to provide structural rigidity and stability under harsh high temperature conditions. After casting the samples were placed in the temperature-controlled curing room of temperature of $23+3^{\circ} \mathrm{C}$ for a period of $24 \mathrm{hrs}$. Afterwards the samples were demolded and placed in the air cooling for an additional period of $24 \mathrm{hrs}$. Figure 4 presents the particle size analysis of the GiD nano powder used in the experimentation. Past researcher tested three sizes of $\mathrm{GiD}$ powder i.e., coarse powder ranging from $50 \mu \mathrm{m}$ to $30 \mu \mathrm{m}$, medium size ranging from $6 \mu \mathrm{m}$ to $3 \mu \mathrm{m}$ and fine size of the powder ranging from $3 \mu \mathrm{m}$ to $1.8 \mu \mathrm{m}$ (Omran \& Tagnit-Hamoua, 2016; Wiese et al., 2015). Through their experimentation it was revealed that larger sized particles resulted in larger deterioration while fine size powder was more suitable for mixing the material with other cementitious compounds as it allowed for ease of penetration into the pours. Furthermore, Sathyanarayanan (2007) tested GiD based paint on the road surface and concluded that traffic flow would wear out the paint coating based on fine sized material in a life span of 0.72.5 years depending upon the location of paint and traffic volume. In light of the above discussion and learning from the experience of the past researchers' (Sathyanarayanan et al., 2007; Wiese et al., 2015) medium size of GiD powder was selected for the presented experimentation. GiD powder was mixed three varying proportions of 5\%, 10\% and $15 \%$ of mass of epoxy resin in order to identify the appropriate percentage of $\mathrm{GiD}$ powder needed to achieve the required intensity and duration of glow. A total of 36 disk samples were molded using three proportion of GiD nano powder as shown in the Figure 5.

Figure 6 depicts the GiD based raised pavement marker in comparison to commercially available Bott's dots presented in day and night light conditions. Bott dots come in a variety of colors, however the most commonly used types are white and yellow which are as presented in Figure 6. It can be seen from the presented experimental evidence that the developed GiD based prototype is able

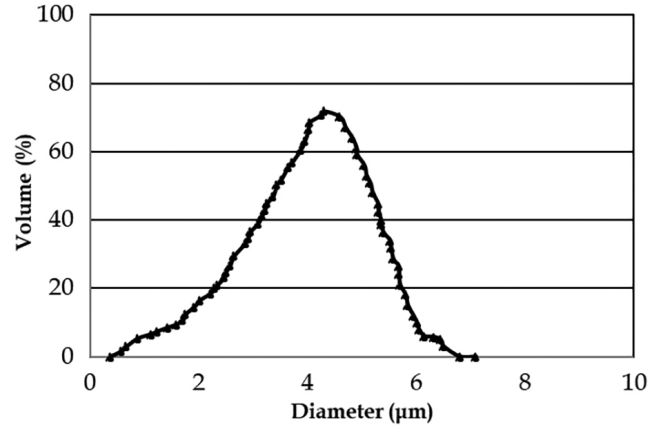

Figure 4. Particle size analysis

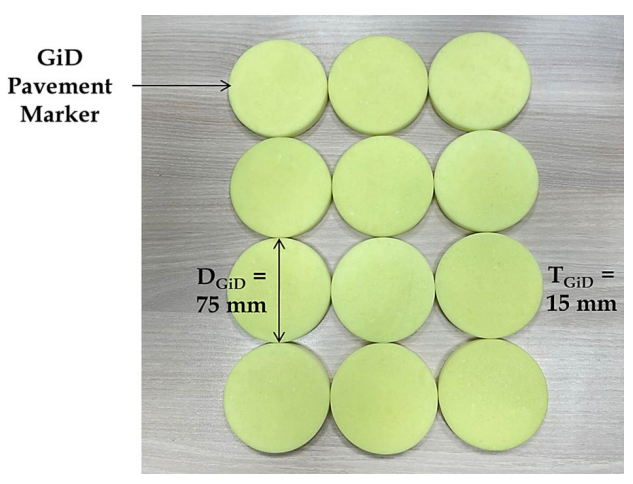

Figure 5. Glow-in-the-dark (GiD) based raised pavement marker specimens (U.S. Patent pending)

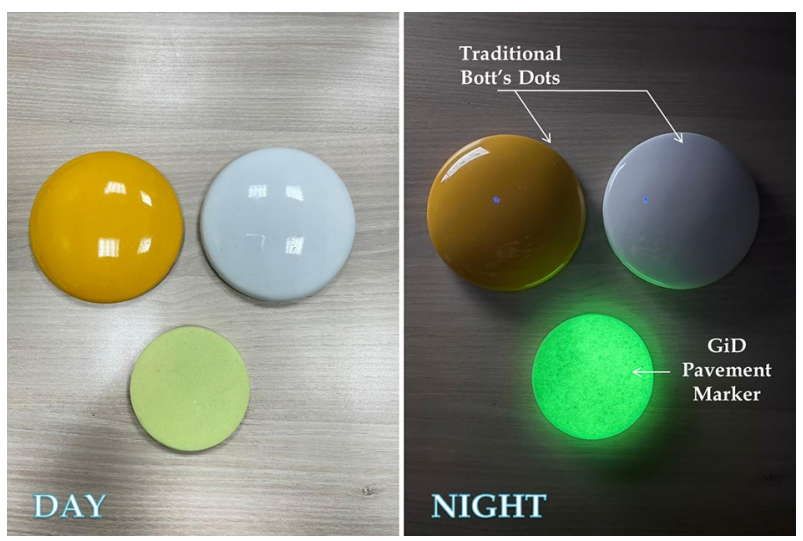

Figure 6. Traditional Bott's dots/turtles/buttons in comparison to Glow-in-the-dark $(\mathrm{GiD})$ raised pavement marker specimen - day and nighttime view

to absorber and store energy during the daytime and emit the energy in the form of visible light during the nighttime. Thermo-mechanical performance testing was conducted in order to ascertain the durability of the developed prototype. The results of the testing are presented in the proceeding section.

\section{Performance testing and results}

\subsection{Compressive strength testing}

Compression testing of the developed prototype was conducted using ASTM D695-15 (American Society for Testing and Materials [ASTM], 2015) standard. Three samples 
from each mix proportion i.e., 5\%, $10 \%$ and $15 \% \mathrm{GiD}$ inclusion, totaling nine samples were tested under monotonically increasing compressive load applied at $5 \mathrm{~mm} /$ min as shown in Figure 7. The objective of this test was to simulate the pressure of vehicle tire passing over the prototype specimens. Table 1 presents the results of the nine samples tested under compressive loading. The average compressive strength of the nine samples was 92.42 $\mathrm{MPa}$. Field investigation from past researchers (Texas Transportation Institute, 2009; AASHTO, 2007; NASA, 2020) related to the causes of failure of RPMs has shown that breakage of Bott's dots is a common cause of failure owing to the brittle nature of materials used for manufacturing followed by dislodging of epoxy resin. Commercially available RPM are also manufactured using steel enclosed reflector casing which are tested using ASTM D4280 (ASTM, 2018a) standards. The typical RPM tested under this standard must be able to sustain $82 \mathrm{MPa}$. Figure 7 also presents the typical cracking pattern of the prototype specimen. From the presented experimentation it was noticed that the samples experienced slight edge cracking and discoloration owing to applied loading, however, no clear breakage of the specimen was recorded during the experimentation. From the presented experimental evidence, it can be deduced that the developed prototype is capable of sustaining the compressive forces applied owing to vehicle loading.

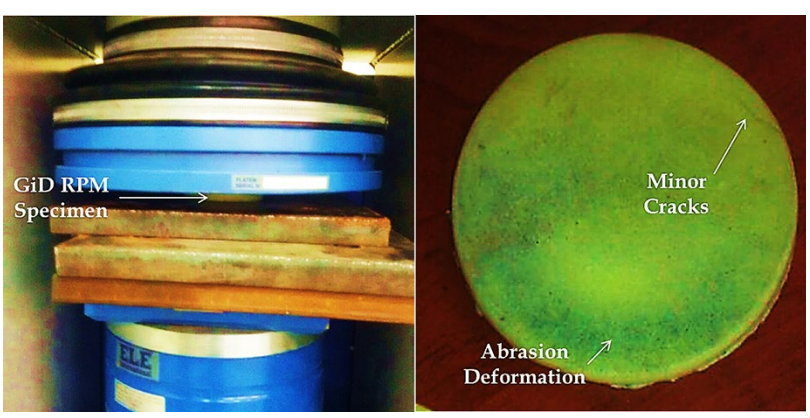

Figure 7. Compression testing of $\mathrm{GiD}$ based RPM specimen

Table 1. Compressive testing result of GiD based RPM

\begin{tabular}{|c|c|c|c|c|}
\hline Sr. No. & GiD Proportion & $\begin{array}{c}\text { Area } \\
\left(\mathrm{mm}^{2}\right)\end{array}$ & $\begin{array}{l}\text { Load } \\
(\mathrm{KN})\end{array}$ & $\begin{array}{l}\text { Comp. Str. } \\
\quad(\mathrm{MPa})\end{array}$ \\
\hline 1 & \multirow{3}{*}{$5 \%$} & 4416 & 404 & 91.55 \\
\hline 2 & & 4416 & 391 & 88.73 \\
\hline 3 & & 4416 & 411 & 93.21 \\
\hline 4 & \multirow{3}{*}{$10 \%$} & 4416 & 401 & 90.99 \\
\hline 5 & & 4416 & 424 & 95.97 \\
\hline 6 & & 4416 & 420 & 95.09 \\
\hline 7 & \multirow{3}{*}{$15 \%$} & 4416 & 418 & 94.74 \\
\hline 8 & & 4416 & 394 & 89.18 \\
\hline 9 & & 4416 & 408 & 92.37 \\
\hline \multicolumn{4}{|c|}{ Average } & 92.42 \\
\hline
\end{tabular}

\subsection{Thermal testing}

Thermal testing was conducted on the developed prototype to judge its suitability of application under real-world conditions. The objective of the research team for this test was to investigate the possibility of melting or deformation owing to increase in temperature. With regards to expected daily functionality of the proposed prototype two tests were developed. The first test was designed to simulate the daily temperature fluctuation and the internal thermal loading that can cause deformation into the shape of the prototype while the second was devised to emulate an extreme condition where a hot bitumen can be cast adjacent to GiD based RPM installed on the walkway, cycle way, bus stand etc. For the first test the specimens were placed in the dry air temperature-controlled laboratory at temperature of $23+3{ }^{\circ} \mathrm{C}$ for a period of $24 \mathrm{hrs}$. Afterwards the specimens were placed in the oven and the temperature was increased to $55^{\circ} \mathrm{C}$ in equal increments of $5^{\circ} \mathrm{C}$ at the rate of increase of $1^{\circ} \mathrm{C}$ per minute. The samples were kept at $55{ }^{\circ} \mathrm{C}$ for 15 mins and then removed and allowed to cool in air. This loading cycle was repeated 12 times on a single specimen. From the experimentation it was recorded that the samples depicted no cracking damage or deformation to the shape.

The second thermal loading test was designed to replicate the extreme condition where a hot bitumen could be placed adjacent to the GiD RPM installed on bicycle ways, walkways, curb stones of bus stand etc. In this case, the air-cooled samples were placed in the over and the temperature was increased to $100{ }^{\circ} \mathrm{C}$ in equal increments of $5{ }^{\circ} \mathrm{C}$ per minute. The samples were kept at $100{ }^{\circ} \mathrm{C}$ for a period of 5 mins and then allowed to cool down to room temperature. From the experiment it was evident that only 15\% GiD RPM samples displayed slight visible deformation owing to thermal expansion properties of the added nano powder. However, since this is an extreme case test and the conditions of extreme temperature remain for a few minutes in real-world setting as the temperature immediately starts to drop once the bitumen is laid on the road surface. Hence, the performance of the specimen can be considered as satisfactory.

\subsection{Skid resistance number test}

Traffic Safety Division (1995) conducted a detailed review of the skid performance of commercially available RPM's. The researchers tested 14 different type of samples using British Pendulum Number (BPN) test which depicts the coefficient of friction and reported that the RPMs showed an average skid resistance number (SRN) of 40 which is below the desired value of 65 and could cause the vehicles to lose control when driving over them under wet and windy conditions.

In light of this discussion the aim of the research team was to develop a GiD based RPM which could perform better in SRN test. In this regards the developed prototype was evaluated in three environmental conditions: (a) sandy; (b) wet; (c) dry, using ASTM E303-93(2018) 
(ASTM, 2018b). The aim of the test was to ascertain the performance under each weather condition. Table 2 presents average of five tests conducted under environmental condition. It is to be brough to the attention of the readers that during skid testing rubber marks were observed on the top surface of the prototype. However, these marking did not affect the luminescence of the prototype, furthermore, these marking were cleaned with water scrubbing. The standard value of SRN for most tricky locations, according to ASTM E303-93(2018) is 65 (ASTM, 2018b). From the presented result it is evident that the developed prototype performs suitable in all weather conditions.

Table 2. Skid resistance value for 15\% GiD based RPM

\begin{tabular}{|c|c|c|c|}
\hline Sr. No. & Area $\left(\mathrm{mm}^{2}\right)$ & Surface Condition & Skid Average \\
\hline 1 & 4416.00 & Sand & 77 \\
\hline 2 & 4416.00 & Wet & 68 \\
\hline 3 & 4416.00 & Dry & 83 \\
\hline
\end{tabular}

\subsection{Fatigue testing}

Fatigue testing of the developed GiD RPM prototype was conducted using ASTM D4280 standard (ASTM, 2018a). The objective of this test was to evaluate the performance of the developed prototype under repeated compressive loading resulting from the passing of vehicle tires. To simulate the field condition of the compressive load generated by the vehicle passing over the GiD RPM, the samples were tested under cyclic loading. The loading cycle started with the increase in applied compressive force up to 88 $\mathrm{MPa}$. The load was kept constant for $5 \mathrm{sec}$, after which the load was removed. This cyclic loading was repeated for 100 times. $88 \mathrm{MPa}$ equates to $95 \%$ of average compressive force achieved during the compressive strength testing. The rational for selecting this load value was to satisfy the ASTM D4280 (ASTM, 2018a) requirement of $82 \mathrm{MPa}$ for steel enclosed reflector RPM.

It is to be brought to the attention of the readers that during the field condition, the load applied over the RPM is sustained for less than a second under normal traffic conditions, however, in the presented research work the load was sustained for $5 \mathrm{sec}$ in each loading cycle. The rational background for this decision was to simulate the worst possible condition of slow-moving traffic. Hence, the choice of time has sustained loading has logical background. Figure 8 presents the sample after fatigue testing along with the nighttime view. It can be seen from the figure that the sample experienced no failure. The abrasions on the surface of the sample were owing to the roughness of the steel plates used for testing. Furthermore, the samples were visible during the nighttime even after the cyclic testing.

\subsection{Glow-in-the-dark testing}

Glow-in-the-dark testing was conducted on the developed prototype to judge its applicability under real-world condition. The objective of the experiment was to judge the

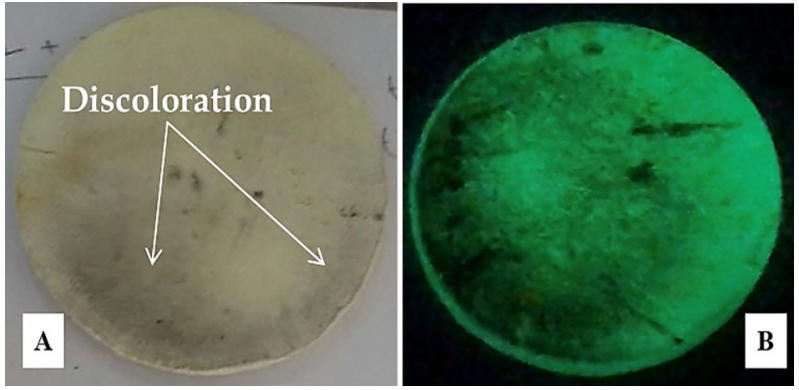

Figure 8. Fatigue test, daytime and nighttime view of GiD Based RPM Specimen after fatigue testing

level of glow i.e., intensity and duration of glow of the developed prototype. In this regards a photometer was used to measure both intensity and duration of the sample in candles per square meter $\left(\mathrm{mcd} / \mathrm{m}^{2}\right)$. The base level of the prototype was established as the minimum light that the human eye can see emitting from the prototype at 0.0032 $\mathrm{mcd} / \mathrm{m}^{2}$ (Matsuzawa et al., 1996; Kostic \& Djokic, 2009; Rojas-Hernandez et al., 2018; Praticò et al., 2018). Since the intensity and duration of the light depends on the percentage of GiD powder included in the prototype along with the excitation duration. Hence, before commencing the test all samples were placed in the dark cover with no visible light for a period of $24 \mathrm{hrs}$. Afterwards, each sample was excited using 150W xenon lamp. Duration and intensity of glow of each sample was recorded. The rationale behind choosing the Xenon lamp as the source of excitation was the logic that since its spectral irradiation emitted by the xenon lamp matches closely with the sun based on spectral irradiance vs wavelength of light, hence, this choice will replicate the real-world lighting condition (Wiese et al., 2015; ASTM, 2020). Furthermore, the distance of the light was adjusted such that the entire surface of the GiD RPM was uniformly covered with the lighting. Three samples with 5\%, $10 \%$ and $15 \%$ GiD material addition were tested for 5, 10 and 15 mins of excitation. The glow-in-the-dark was measured such that after exciting the specimen for the desired amount of time, the lamp was switched off and the photometer was placed on top of the samples after 30 seconds. Data recording was initiated and continued for a period of $8 \mathrm{hrs}$. The rational for recording data for 8 hrs was the logic that the GiD samples need to produce visible light only in the nighttime.

It is worth highlighting that the standard accepted for escape route marking industry is 100 times higher than the base value of $0.0032 \mathrm{mcd} / \mathrm{m}^{2}$ i.e., $0.32 \mathrm{mcd} / \mathrm{m}^{2}$ (Matsuzawa et al., 1996). Figure 9 presents the experimental evidence of the glow-in-the-dark testing. From the presented experimental evidence, it is clear that as the GiD nano powder proportion increases the intensity of glow increases. However, percentage of GiD nano powder had little effect on the duration of glow. From the presented experimental evidence, it can be concluded that once the GiD material is completely charged/excited then the material will keep emitting visible light for the needed amount of duration. However, the intensity of duration is a factor 


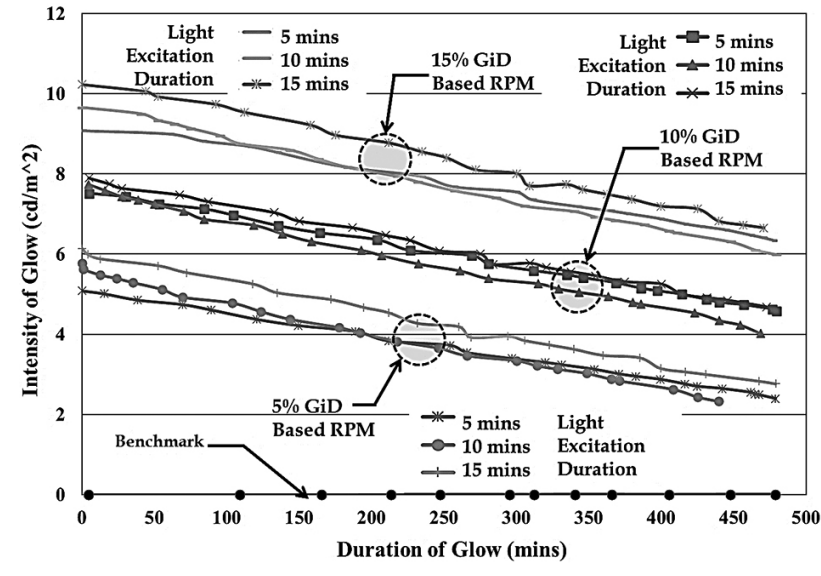

Figure 9. Glow intensity and duration with respect to varying percentage of $\mathrm{GiD}$ nano powder in developed $\mathrm{GiD}$

based RPM prototype

of GiD proportion. Furthermore, streetlights and vehicle light also contribute towards charging the GiD RPM. From the result it can be seen that as the GiD component increases from $5 \%$ to $10 \%$ the gain in intensity was $13 \%$ while $23 \%$ gain in intensity was observed for GiD component increase of $10 \%$ to $15 \%$. Furthermore, past published experimental research work (Saleem \& Blaisi, 2019) has shown that $\mathrm{GiD}$ component larger than $20 \%$ has negligible performance gains as compared to cost increase. Hence, it can be deduced that $15 \%$ of $\mathrm{GiD}$ nano proportion can be considered as desirable from the perspective of glow intensity, duration and cost. The cost comparison of the developed GiD based RPM as compared to traditional bott's dots along with real-world testing demonstration video evidence is presented in the proceeding section.

\section{Real-world application test}

The objective of this section is to present to the readers the real-world testing of the developed prototype. It is to be highlighted that the developed prototype is for roads with speed limits of $50 \mathrm{~km} / \mathrm{hrs}$ and is primarily designed for community roads. Although it is possible to develop large variations in shape and sizes of the proposed prototype. The main aim of the presented research work is to provide proof-of-concept of the using GiD based RPM for improve visibility and edge detection. Hence the choice of road condition and geometry of the prototype has rational background. In light of the above-mentioned case conditions, it was a full-sized SUV was chosen as the vehicle for applying tire compressive loading. 100 passes of the vehicle were performed on the presented prototype.

Figure 10 presents the exerts from the demo video where a full-sized SUV loading was passed over the GiD RPM prototype for 100 times. The test site was a community road inside the university housing compound with a speed limit of $50 \mathrm{~km} / \mathrm{hrs}$. The objective of this test was to ascertain the performance of the developed prototype under real-world vehicle loading and environmental conditions. From the experiment, no degradation and discol-

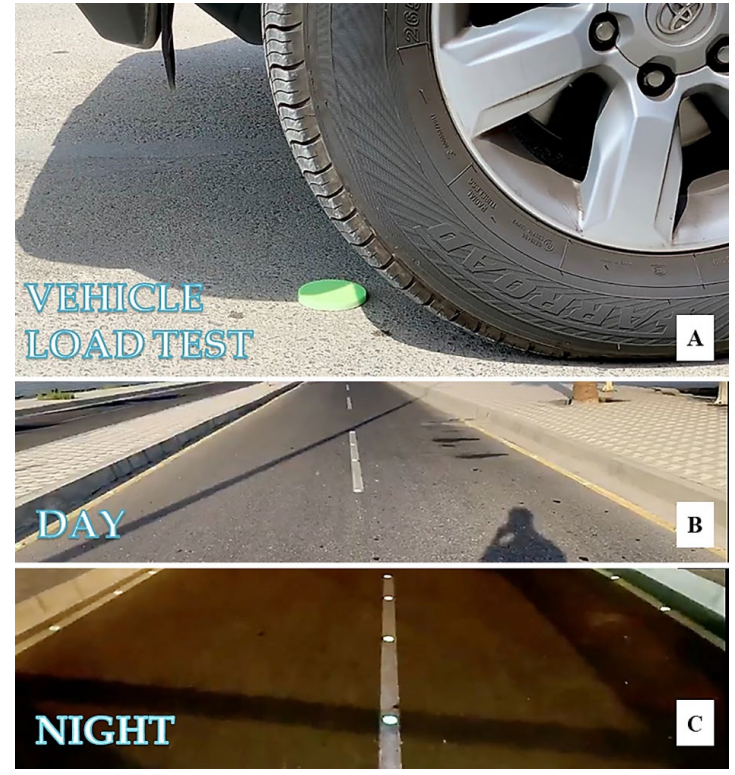

Figure 10. Exerts from the demo video of GiD based RPM: a - Vehicle cyclic tire loading test; b - Day time view; c - Nighttime view

oration were observed after the repeated vehicle loading. Furthermore, the daytime and night view of the GiD RPM are also presented to the readers to allow to judge the increased visibility owing to the developed GiD RPM.

It is worth highlighting that the demo unit installed on the roadway were not charged for the full day owing to limitation of the test site. Furthermore, it was also observed that the prototype was able to absorb energy from the streetlights thus increasing the glow and adding to overall safety and ambiance of the roadway.

\section{Real-world maintenance strategies}

The objective of this section is to bring to the attention of the readers the various challenges associated with the application and maintenance of the proposed prototype. For application it is recommended to use epoxy resin as a binder for attaching the GiD RPM to the road surface. Since, the application of the developed prototype ranges from use inside the building, parking areas, airports, roads, bicycle lanes, walkways. Hence, the amount of epoxy resin needed for installation is an area of further research and development. From the field experience, it is well documented that the traditional Bott dots suffer rupture failure owing to the brittle materials used for their construction, furthermore, their top surface is slippery in nature which is a cause of concern for traffic safety (Texas Transportation Institute, 2009; AASHTO, 2007; NASA, 2020).

The presented developed GiD RPM has the advantage that the top surface is not slippery, however, this provides an additional challenge that the top surface of the prototype is prone to discoloration owing to type marks. However, laboratory testing has revealed that the discoloration can be removed by washing and scrubbing the GiD RPM. Considering this testing, it is recommended to apply lu- 
bricant based brushing of the prototype under real-world traffic application. It is worth highlighting that this is an achievable with minimal modification to existing road cleaning equipment. Hence, this aspect of the presented GiD RPM is a challenge that can be addressed with little efforts in the real-world application conditions.

\section{Cost comparison with traditional RPM}

According to Center for Disease Control and Prevention [CDC] (2020) each year 1.35 million people lose their lives to traffic accidents each year around the globe. 3700 people die each day resulting in a total loss of US\$ 1.8 trillion to the global economy. In this regards any innovation and breakthrough in traffic safety will have a major impact on the living standard of people around the world.

In light of the above discussion real-world cost comparison of the presented prototype is conducted to evaluate the increase in cost owing to the use of GiD material. It is worth mentioning that the researchers were aware that using the GiD nano powder will lead to cost increase, however, the safety and quality of life improvement gained from the use of GiD based RPM should also be taken into context when comparing the numerical figures presented below. The cost comparison is conducted for $15 \%$ addition of GiD based RPM in comparison to traditional commercially available Bott's dots assuming that the cost of labor, handling, placement, transport and installation is the same for a given site. Since the installation mechanism is the same for both devices, hence the above-mentioned assumption has rational background. The details of the cost comparison are as provided in Table 3.

Table 3. Cost comparison

\begin{tabular}{|l|l|}
\hline \multicolumn{2}{|c|}{ Traditional Bott's dots } \\
\hline $\begin{array}{l}\text { Typical spacing of RPM for } 1000 \mathrm{~m} \\
\text { central lane }\end{array}$ & $40 \mathrm{~m}$ \\
\hline Total number of RPM in $1000 \mathrm{~m}$ & 25 \\
\hline Cost of a Traditional Bott's Dots & US\$ 4.0 (SR 14) \\
\hline $\begin{array}{l}\text { Total Cost of Installation for Traditional } \\
\text { Bott's Dots }\end{array}$ & US\$ 100 (SR 375) \\
\hline \multicolumn{2}{|c|}{ GiD RPM } \\
\hline Cost of 15\% GiD based RPM & US\$ 11.2 (SR 42) \\
\hline Total Cost of GiD based RPM & US\$ 280 (SR 1050) \\
\hline Percentage increase in Cost & 2.80 times or 280\% \\
\hline
\end{tabular}

It is worth mentioning that the presented prices used in the cost comparison are for laboratory sample preparation. These costs can be reduced when procurement and manufacturing are conducted on a large scale.

\section{Conclusions}

The value and contribution of the presented experimental pioneering proof-of-concept research work to the body of knowledge is as summarized below:
- A glow-in-the-dark concrete based raised pavement marker is presented which has the ability to provide visible light thus eradicating the need of retroreflection and electroluminescence.

- GiD based RPM specimens depicted good durability performance under mechanical and thermal loading.

- Glow-in-the-dark testing has revealed that the glow intensity increases with the increase in percentage of nano powder. Furthermore, the glow duration is not affected after the material has been charged for 5 mins.

- The demo video detailing the application of the GiD based RPM depicted increased visibility of lane markers and road edge which added to the safety of the road users.

\section{Acknowledgements}

The authors are grateful to the Deanship of Scientific Research (DSR) at Imam Abdulrahman Bin Faisal University, IAU (Previously: University of Dammam), Kingdom of Saudi Arabia for the continued support, cooperation and guidance.

\section{Data availability}

Some or all data, models, or code that support the findings of this study are available from the corresponding author upon reasonable request.

\section{Conflict of interest}

The authors declare that they have no conflict of interest. All the funding sources have been disclosed and are acknowledged in the manuscript.

\section{References}

American Association of State Highway and Transportation Officials. (2007). The oval shape raised pavement markers (Report No. SS. 27).

American Society for Testing and Materials. (2015). Standard test method for compressive properties of rigid plastics (No. ASTM D695-15). ASTM International, West Conshohocken, PA.

American Society for Testing and Materials. (2018a). Standard specification for extended life type, nonplowable, raised retroreflective pavement markers (No. ASTM D4280). ASTM International, West Conshohocken, PA.

American Society for Testing and Materials. (2018b). Standard test method for measuring surface frictional properties using the British pendulum tester (No. ASTM E303-93(2018)). ASTM International, West Conshohocken, PA.

American Society for Testing and Materials. (2020). Standard tables for reference solar spectral irradiances: Direct normal and hemispherical on $37^{\circ}$ tilted surface (No. ASTM G17303(2020)). ASTM International, West Conshohocken, PA.

Bahar, G., Masliah, M., Erwin, T., Tan, E., \& Hauer, E. (2006). Pavement marking materials and markers: Real-world relationship between retroreflectivity and safety over time (NCHRP Web Only Document 92). Transportation Research Board, Washington, DC. 
BBC News. (2014a). Glow in the dark road unveiled in the Netherlands. http://www.bbc.com/news/technology-27021291

BBC News. (2014b). Netherlands glow-in-the dark cycle path unveiled. https://www.bbc.com/news/av/technology-30024883/ netherlands-glow-in-the-dark-cycle-path-unveiled

Blamire, J. (2003). Atomic structure. The nature of electron and energy. http://www.brooklyn.cuny.edu/bc/ahp/LAD/C3/C3 elecEnergy.html

Britannica. (2020). Orbits and energy levels. https://www.britannica.com/science/atom/Orbits-and-energy-levels

British Standards Institution (1927). Street lighting (British Standard Specification 307).

Cafiso, S., \& D’Agostino, C. (2016). Assessing the stochastic variability of the benefit-cost ratio in roadway safety management. Accident Analysis \& Prevention, 93, 189-197. https://doi.org/10.1016/j.aap.2016.04.027.

Center for Disease Control and Prevention. (2020). Global road traffic crash deaths, injuries, and costs.

Euro NCAP. (2020). The European New Car Assessment Programme. https://www.euroncap.com/en

Giuliani, F., \& Autelitano, F. (2014). Revêtements routiers photoluminescents: étude expérimentale préliminaire en laboratoire [Photoluminescent road surface dressing: a first laboratory experimental investigation]. Matériaux Techniques, 102(6-7), 603. https://doi.org/10.1051/mattech/2014030

Hautière, N., Dumont, E., Brémond, R., \& Ledoux, V. (2009). Review of the mechanisms of visibility reduction by rain and wet road. In $8^{\text {th }}$ International Symposium on Automotive Lighting. München, Herbert Utz Verlag.

Jarašūnienė, A., \& Jakubauskas, G. (2007). Improvement of road safety using passive and active intelligent vehicle safety systems. Transport, 22(4), 284-289.

https://doi.org/10.3846/16484142.2007.9638143

Kostic, M., \& L. Djokic, L. (2009). Recommendations for energy efficient and visually acceptable street lighting. Energy, 34(10), 1565-1572. https://doi.org/10.1016/j.energy.2009.06.056

Mai, J. (2018). China's 'solar highway' was victim of heavy traffic and bad design, not thieves, report says. South China Moring Post. https://www.scmp.com/news/china/society/article/2131241/chinas-solar-highway-was-victim-heavy-trafficand-bad-design-not

Matsuzawa, T., Aoki, Y., Takeuchi, N., \& Murayama, Y. (1996). A new long phosphorescent phosphor with high brightness, $\mathrm{SrAl}_{2} \mathrm{O}_{4}: \mathrm{Eu}^{2+}, \mathrm{Dy}^{3+}$. Journal of The Electrochemical Society, 143(5), 2670. https://doi.org/10.1149/1.1837067

McGrath, T. (2014). The Netherlands debuts a futuristic highway that glows in the dark. https://www.pri.org/stories/2014-04-15/ netherlands-debuts-futuristic-highway-glows-dark

Nance, J., \& Sparks, T. D. (2020a). From streetlights to phosphors: A review on the visibility of roadway markings. Progress in Organic Coatings, 148, 105749.

https://doi.org/10.1016/j.porgcoat.2020.105749

Nance, J., \& Sparks, T. D. (2020b). Comparison of coatings for SrAl2O4: Eu2+, Dy3+powder in waterborne road stripping paint under wet conditions. Progress in Organic Coatings, 144, 105637. https://doi.org/10.1016/j.porgcoat.2020.105637

National Aeronautics and Space Administration. (2020). Unified facilities guide specifications - pavement markings (NASA Research Report).

Okada, J. (2015). Lotus ceramics for counteracting urban heat island effects. In F. Pacheco-Torgal, J. Labrincha, L. Cabeza, \& C.-G. Granqvist (Eds.), Eco-efficient materials for mitigating building cooling needs. Design, properties and applications (pp. 195-213). Elsevier.

https://doi.org/10.1016/B978-1-78242-380-5.00007-8

Omran, A., \& Tagnit-Hamoua, A. (2016). Performance of glasspowder concrete in field applications. Construction and Building Materials, 109, 84-95.

https://doi.org/10.1016/j.conbuildmat.2016.02.006

Praticò, F. G., Noto, S., \& Moro, A. (2016). Optimisation of photoluminescent painting treatments on different surface layers. In Proceedings of $4^{\text {th }}$ Chinese-European Workshop on Functional Pavement Design (CEW 2016). Taylor \& Francis Group. https://doi.org/10.1201/9781315643274-168

Praticò, F. G., Vaiana, R., \& Noto, S. (2018). Photoluminescent road coatings for open-graded and dense-graded asphalts: Theoretical and experimental investigation. Journal of Materials in Civil Engineering, 30(8), 04018173.

https://doi.org/10.1061/(ASCE)MT.1943-5533.0002361

Rojas-Hernandez, R. E., Rubio-Marcos, F., Rodriguez, M. Á., \& Fernandez, J. F. (2018). Long lasting phosphors: $\mathrm{SrAl}_{2} \mathrm{O}_{4}: \mathrm{Eu}$, Dy as the most studied material. Renewable and Sustainable Energy Reviews, 81(Part 2), 2759-2770.

https://doi.org/10.1016/j.rser.2017.06.081

Saleem, M. (2016). Investigating the effect of impact loading generated due to moving truck wheel on smart road lane separator. Qassim University Journal of Engineering and Computer Sciences, 9(2), 85-99.

Saleem, M. (2020). GiD raised lane separator [Video]. YouTube. https://www.youtube.com/watch?v=yIg8zz6T2ys

Saleem, M., \& Blaisi, N. I. (2019). Development, testing, and environmental impact assessment of glow-in-the-dark concrete. Structural Concrete, 20, 1792-1803.

https://doi.org/10.1002/suco.201800221

Saleem, M., Shami, M. \& Najjar, M. (2017). Development of smart material lane separator for increased traffic safety. Journal of Construction Engineering and Management, 143(5), 04016129. https://doi.org/10.1061/(ASCE)CO.1943-7862.0001240

Santamouris, M. (2013). Using cool pavements as a mitigation strategy to fight urban heat island. A review of the actual developments. Renewable and Sustainable Energy Reviews, 26, 224-240. https://doi.org/10.1016/j.rser.2013.05.047

Sathyanarayanan, S. (2007). Semi-parametric modeling of pavement marking visibility degradation [PhD dissertation]. Pennsylvania State University, USA.

Smadi, O., Hawkins, N., Aldemir-Bektas, B., Carlson, P., Pike, A., \& Davies, C. (2014). Recommended laboratory test for predicting the initial retroreflectivity of pavement markings from glass bead quality. Transportation Research Record: Journal of the Transportation Research Board, 2440, 94-102.

https://doi.org/10.3141/2440-12

Solar Roadways Incorporated. (2020). Products. http://solarroadways.com/Product/Applications

State of California Department of Transportation. (2018). Markings.

STG Aerospace. (2020). The highest performing photoluminescent floor path marking system.

Teo, H. T., \& Tan, Y. S. (2020). Fast object detection on the road. In 2020 IEEE Asia Pacific Conference on Circuits and Systems (APCCAS) (pp. 173-176). Ha Long, Vietnam. https://doi.org/10.1109/APCCAS50809.2020.9301706

Texas Transportation Institute. (2009). Development of measures to improve field performance of retroreflective raised pavement markers. Raised pavement marker improvements. 
Traffic and Safety Division. (1995). Skid testing of pavement markings (Final Report, TSD-277-75).

Utah Department of Transportation. (2012). Pavement marking paint.

Wiese, A., Washington, T., Tao, B., \& Weiss, W. J. (2015). Assessing the performance of glow in the dark concrete. Transportation Research Record: Journal of the Transportation Research Board, 2508(1), 31-38. https://doi.org/10.3141/2508-04

Zitoun, D., Bernaud, L., \& Manteghetti, A. (2009). Microwave synthesis of a long-lasting phosphor. Journal of Chemical Education, 86(1), 72. https://doi.org/10.1021/ed086p72

\section{APPENDIX}

Demo Video Link is https://www.youtube.com/watch?v= yIg8zz6T2ys and QR Code:

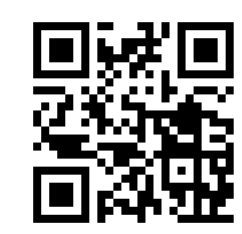

